- When restoring the edentulous maxilla with implants one of the major decisions to make is often whether the patient should be restored with a fixed or removable prosthesis.

- The number of implants to be placed depends on quality of bone, anticipated force and arch form.

- Removable restorations require more maintenance than their fixed counterparts.

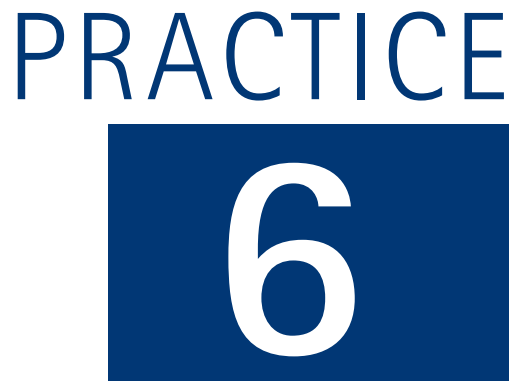

VERIFIABLE CPD PAPER

\title{
Treatment planning of the edentulous maxilla
}

\author{
S. Jivraj, ${ }^{1}$ W. Chee ${ }^{2}$ and P. Corrado ${ }^{3}$
}

The predictability of successful osseointegrated implant rehabilitation of the edentulous jaw as described by Branemark et al., ${ }^{1}$ introduced a new era of management for the edentulous predicament. Implant rehabilitation of the edentulous maxilla remains one of the most complex restorative challenges because of the number of variables that affect both the aesthetic and functional aspect of the prosthesis. ${ }^{2}$ Among the prosthesis designs used to treat the edentulous maxilla are fixed or removable implant-supported restorations. Since the aesthetic requirements and preoperative situation of each patient varies, considerable time must be spent on accurate diagnosis to ensure patient desires are satisfied and predictable outcomes are achieved. The purpose of this article is to compare the treatment options and prosthesis designs for the edentulous maxilla. Emphasis will be placed on diagnosis and treatment planning. Criteria will be given to guide the practitioner in deciding whether a fixed or removable restoration should be placed. This objective will be accomplished through the review of cases with regard to varying design considerations and factors that influence the decision-making process.

\begin{tabular}{|c|}
\hline IMPLANTS \\
\hline 1. Rationale for dental implants \\
\hline $\begin{array}{l}\text { 2. Treatment planning of implants in } \\
\text { posterior quadrants }\end{array}$ \\
\hline $\begin{array}{l}\text { 3. Treatment planning of implants in } \\
\text { the aesthetic zone }\end{array}$ \\
\hline $\begin{array}{l}\text { 4. Surgical guidelines for dental } \\
\text { implant placement }\end{array}$ \\
\hline $\begin{array}{l}\text { 5. Immediate implant placement: } \\
\text { treatment planning and surgical } \\
\text { steps for successful outcomes }\end{array}$ \\
\hline $\begin{array}{l}\text { 6. Treatment planning of the } \\
\text { edentulous maxilla }\end{array}$ \\
\hline $\begin{array}{l}\text { 7. Treatment planning of the } \\
\text { edentulous mandible }\end{array}$ \\
\hline $\begin{array}{l}\text { 8. Impressions techniques for implant } \\
\text { dentistry }\end{array}$ \\
\hline $\begin{array}{l}\text { 9. Screw versus cemented implant } \\
\text { supported restorations }\end{array}$ \\
\hline $\begin{array}{l}\text { 10. Designing abutments for } \\
\text { cement retained implant supported } \\
\text { restorations }\end{array}$ \\
\hline 11. Connecting implants to teeth \\
\hline $\begin{array}{l}\text { 12. Transitioning a patient from teeth } \\
\text { to implants }\end{array}$ \\
\hline $\begin{array}{l}\text { 13. The role of orthodontics in } \\
\text { implant dentistry }\end{array}$ \\
\hline $\begin{array}{l}\text { 14. Interdisciplinary approach to } \\
\text { implant dentistry }\end{array}$ \\
\hline $\begin{array}{l}\text { 15. Factors that affect individual } \\
\text { tooth prognosis and choices in } \\
\text { contemporary treatment planning }\end{array}$ \\
\hline 16. Maintenance and failures \\
\hline
\end{tabular}

As in all phases of dentistry diagnosis is critical in obtaining a predictable outcome. An incomplete or erroneous diagnosis can yield unsatisfactory results for both the patient and treating clinician.

Historically most of the research for implant rehabilitation of edentulous patients was conducted in the mandible. Due to the reduced denture bearing surface of the mandible and the mobility of the tongue, patients often complained of instability of the denture and an inability to adapt to a removable prosthesis. Many prostheses designs were evaluated ranging from subperiosteal implants to implants supported complete dentures.

Patients are more likely to wear and accommodate to a maxillary denture compared to its mandibular counterpart. Aesthetics are satisfactory and the greater retention, support and

${ }^{*}$ Chairman, Section of Fixed Prosthodontics and Operative Dentistry, University of Southern California School of Dentistry / Private Prosthodontics Practitioner, Burbank, California; ${ }^{2}$ Ralph W. and Jean L. Bleak Professor of Restorative Dentistry, Director of Implant Dentistry at the University of Southern California School of Dentistry / Private Prosthodontics Practitioner, Pasadena, California: ${ }^{3}$ Private Practice, Verona, Italy

${ }^{*}$ Correspondence to: Dr Sajid Jivraj, School of Dentistry, Rm. 4375 University Park, University of Southern California, Los Angeles, CA 90089-0641, USA

Email:jivraj@usc.edu

\section{Refereed Paper}

๑ British Dental Journal 2006; 201: 261-279

DOI: $10.1038 /$ sj.bdj.4813952 stability are also well documented. Patients are also more likely to wear a maxillary prosthesis for longer periods of time before complications arise. When implant rehabilitation of the edentulous maxilla was required the principles followed the same as that of the edentulous mandible. Screw retained prostheses were fabricated with cantilever pontics. When there was excessive resorption, long standard abutments were installed which entered the oral cavity and the prosthesis was built on top of that. These procedures were acceptable for the mandibular prostheses however the open interproximal spaces in the maxilla would compromise both the aesthetics and function.

Following the same prosthetic concepts for the maxilla as existed in the mandible is not feasible. The long term prognosis for implants in the maxilla is less secure than that of the edentulous mandible. ${ }^{1}$ Following tooth extraction in the anterior part of the maxilla horizontal bone resorption is almost twice as pronounced as vertical resorption. ${ }^{3}$ The vertical distance between the alveolar crest and the base of the nasal sinuses provides a limiting factor for placement of implants. In the posterior maxilla vertical and horizontal atrophy occur at about the same rate, in addition there is pneumatisation of the maxillary sinuses. The width of the ridge is usually sufficient; however, the limiting factor is the vertical distance between the crest and the base of the sinuses. The reduced quantity and quality 
of bone in the maxilla together with increased aesthetic demands makes treatment planning more complex. A different approach based on the ultimate aesthetic outcome is required compared to that of the edentulous mandible where function is the more critical factor.

\section{DIAGNOSIS}

George Bernard Shaw once said 'One of the most dangerous diseases is diagnosis'. The decision making parameters when rehabilitating patients requires the clinician to make a decision as to whether a fixed or a removable prosthesis would be more suitable. A patient presenting with a satisfactory complete denture requesting transition to an implant supported restoration may be a difficult patient to satisfy. Patients must be told about the risks and potential pitfalls of treatment. Informed consent must include surgical risks of treatment as well as a realistic assessment of whether the patient's chief complaint can be addressed and their expectations satisfied.

When restoring the edentulous maxilla with implants, one of the major decisions to make is often whether the patient should be restored with a fixed or removable prosthesis. Several designs can be used to restore patients. With overdenture type designs we can obtain support from both the implants and the mucosa; when there are enough fixtures the restoration can be entirely implant supported.

Zitzmann and Marinello ${ }^{4}$ described in detail parameters that need to be evaluated. A fixed restoration should not be promised to a patient until all diagnostic criteria are evaluated. These criteria must include quality and quantity of bone available to support implants, lip line, lip support and aesthetic demands. Implants should not be placed till a definitive treatment plan has been established as implant positions may vary depending on type of prostheses to be delivered (Figs 1-2).

\section{EXTRA-ORAL EXAMINATION \\ Facial and lip support}

One of the best diagnostic tools is the patient's existing maxillary denture. The clinician can evaluate the patient's denture to determine what likes and dislikes there are regarding aesthetics, speech and function. Each point should be noted for improvements in the new restoration.

There is always a tendency for patients to prefer fixed over removable prostheses. It is the restorative dentists' responsibility to determine if this is feasible. Facial support is an important decision in this regard. Assessment of the patient's facial support with and without the denture in place with the patient facing forward and in profile needs to be made so we can determine which type of prostheses would be more suitable (Figs 3- 4).

Facial support if inadequate is obtained mainly by the buccal flange of a removable restoration (Figs 5-6). Lip support is derived from the alveolar ridge shape and cervical crown contours of the anterior teeth. Resorption of the edentulous maxilla proceeds cranially and medially and this often results in a retruded position of the anterior maxilla. ${ }^{3}$

When evaluating a diagnostic set up with the anterior teeth in proper relation to the lip, the position of the anterior teeth are often anterior to the alveolar ridge. Depending on the severity of the resorption there can be a discrepancy between the ideal location of the teeth and the ridge. This in turn leads to a discrepancy of the anticipated position of the implants in relation to the teeth. This discrepancy must be taken into consideration to achieve a prosthesis that satisfies the parameters of adequate speech, lip support, sufficient tongue space and patient acceptance. When deemed to be large the discrepancy can only be managed with the flange of a removable prosthesis (Figs 7-10). The patient must be made aware of this from the outset and must be told unless extensive grafting procedures are carried out it is unlikely that a fixed restoration can be provided.

\section{Smile line and lip length}

The movement of the upper lip during speech and smiling should be evaluated. Tjan et al. ${ }^{5}$ described the average smile as having the position of the upper lip such that 75\% to 100\% of the of the maxillary incisors and interproximal gingiva are displayed. In a high smile line additional gingiva was exposed and in a low smile line less than 75\% of the maxillary anterior teeth are displayed. Patients should be asked to smile with and without the denture in place (Figs 11-12). If the alveolar ridge is displayed during smiling the aesthetics can be very challenging as the junction between the restoration and the gingival complex will be visible. Lip support should also be evaluated as it influences the position of the maxillary anterior teeth. In a patient with a short upper lip the maxillary anterior teeth will be exposed in repose whereas in patients with a long upper lip the anterior teeth will usually be covered. A long upper lip is a more favourable situation for the treating restorative dentist (Figs 13-14).

\section{INTRA-ORAL EXAMINATION \\ Thickness of the mucosa}

The mucosal quality can be assessed by palpation, sounding or with the help of radiographs. Often in edentulous patients the interdental papillae is absent. When a tooth is lost the interseptal bone disappears and the bone remodels. What is often the result is a flattened papilla. The papilla height is also depressed as there is lack of interproximal contacts.

When papillae are lost it is very difficult if not impossible to regenerate it. Patients must be told that achieving the papillary architecture that existed prior to the extraction of their teeth is unlikely. This illusion is created by manipulating the soft tissues with ovate pontics and varying the position of the interproximal contact. On occasion when implants are in the incorrect position, soft tissue is replaced 
by using gingival coloured ceramics (Figs 1516). It is imperative that the patient preview the final result through the use of provisional restorations. In some instances there is excessive hard and soft tissue loss and the appearance of interdental papilla can only be made up through the use of gingival coloured ceramics or acrylic resin (Figs 17-18). A thick mucosa is easier to mould for an interimplant trigonum than a thin mucosa. Thick mucosa can also help hide abutment margins and facilitates correct emergence of the clinical crown. In some cases where angulated abutments are required the mucosa can facilitate hiding the pronounced titanium collar. If the patient presents with very thin tissue consideration must be given to soft tissue grafting in order to change the tissue type to a more favourable one.

\section{Bone quality and quantity}

Upon consideration of bone quantity, bone quality, resorptive patterns and maxillomandibular relationship it usually becomes apparent that the actual amount of bone available for placement of implants in the edentulous maxilla may not only be limited but may also be present in areas remote from the original site of the natural teeth. In the pre maxilla the tooth position may be much further forward than the implant position and this may pose certain biomechanical disadvantages. In the posterior maxilla the resorption pattern may be so severe that a cross bite relationship may have to be used or alternatively the tooth position may have to be cantilevered facially so as to re-create the vertical and horizontal tooth relationships that existed prior to extraction.

The clinician's ability to evaluate the maxillary bone both quantitatively and qualitatively makes this one of the most challenging sites for successful implant placement.

Visual examination with and without the denture in place will give the clinician an idea of the lip and facial support required and some idea as to whether a fixed or removable restoration would be more appropriate. However, visual examination cannot reveal sufficient information about the location, volume, width and degree of mineralisation of the bone under the soft tissues. ${ }^{2}$ Computed tomography scans and tomograms reveal the three dimensional architecture of the bone and provide the surgeon with precise representation of the availability and location of bone (Figs 19-20). To obtain maximal benefit from such a scan a radiographic template is highly recommended. ${ }^{6}$ Titanium pins or gutta percha markers should be incorporated into an acrylic resin duplicate of the diagnostic denture set up (Figs 21-22). The markers are oriented perpendicular to the occlusal plane and should end apically at the height of the prospective clinical crown margin. ${ }^{2}$

CT scans are extremely useful in evaluating the trajectory of the bone in the posterior maxilla. When a patient has been edentulous for a significant period of time, pneumatisation of the sinuses makes placement of implants very difficult. Maxillary sinus lift procedures are frequently performed to create adequate bone volume for predictable implant placement. ${ }^{7,8}$ The donor site varies depending on the volume of bone required. Bone from the iliac crest is often harvested when both sinuses require augmentation. Augmentation of the sinuses via iliac bone crest grafting can be a traumatic procedure and patients often request alternative options. With information from the CT scan implants can be inclined to avoid the maxillary sinuses, ${ }^{9}$ or alternative procedures that use existing anatomical sites that offer reduced morbidity and minimal invasion of the existing structures can be used.

Zygomatic implants can be placed to engage the zygomatic bone inferolateral to the orbital rim and provide anchorage for a fixed prosthesis in conjunction with anterior implants. ${ }^{10}$ Implants can also be placed in the maxillary tuberosity to provide support (Figs 23-26). ${ }^{11}$

Clinically Lekholm and Zarb ${ }^{12}$ have proposed a classification of jaw shape and quality which is useful when planning treatment for the edentulous maxilla. They classified edentulous maxillae and mandibles into five shapes according to the degree of resorption, shape A, having minimal resorption and shape E, being severely resorbed. Bone quality was classified into four patterns (1 through 4) depending on the amount and type of cortical bone present (Figs 19-20). In the edentulous maxilla type 3 or type 4 bone quality is often found. This quality of bone often dictates over engineering at time of implant placement. Additional implants are placed when the surgeon experiences bone of poor quality, the rationale being if one implant were to fail the restorative dentist would still be able to progress with the anticipated prosthesis.

\section{Inter arch space}

Jaw shape has a significant influence on prosthesis design. The resorption of alveolar bone has been a considerable issue in prosthodontics for as long as clinicians have tried to replace missing intra-oral structures.

To accommodate adequate designs, different types of restorations require different dimensional tolerances. Accurately mounted casts are critical in assessing prosthetic space limitations. Spatial constraints must be considered as a matter of practicality. The limiting factor in edentulous patients is the available interarch space. ${ }^{13}$ An efficient method of evaluating inter arch space in a patient with an edentulous maxillary arch is to construct a diagnostic putty cast. A facebow record is made with the patient's denture in situ. Putty is inserted into the intaglio of the patient's denture and this is then mounted on the upper member of an articulator. In this manner we now have a replica of the patient's maxillary denture bearing area. An impression is then made of the opposing arch and a diagnostic cast poured. Occlusal registrations are made between the mandibular arch and the 


\section{PRACTICE}

Fig. 1 (left) Extra-oral factors that need to be evaluated (Modified from Zitzmann NU and Marinello $\mathrm{CP}^{4}$ )

Fig. 2 (right) Intra-oral factors that need to be evaluated (Modified from Zitzmann NU and Marinello $\mathrm{CP}^{4}$ )
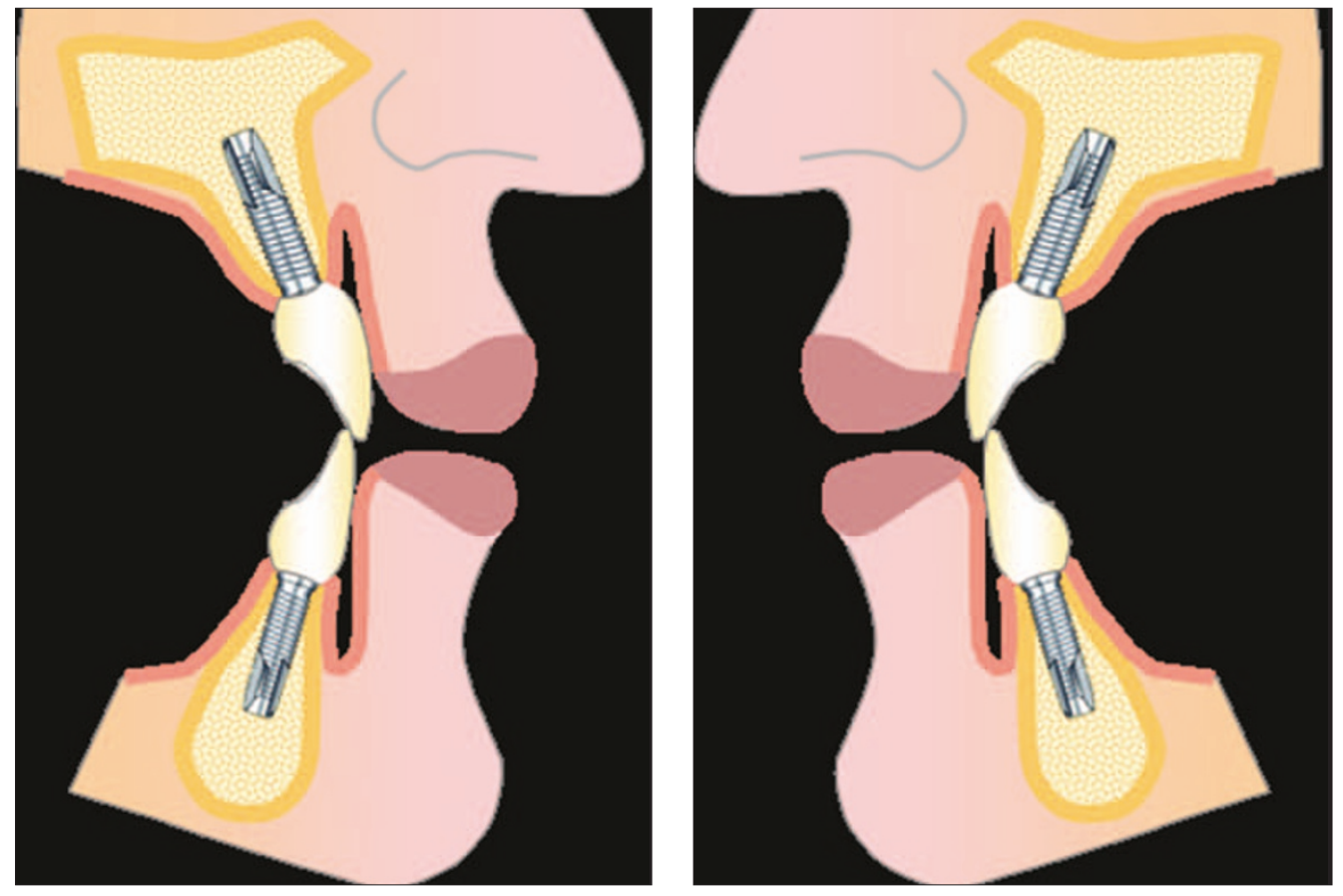

Fig. 3 (left) Lip support with denture, lip looks over-supported

Fig. 4 (right) Lip support without denture. Patient's appearance in profile is satisfactory indicating that a flange will not be required
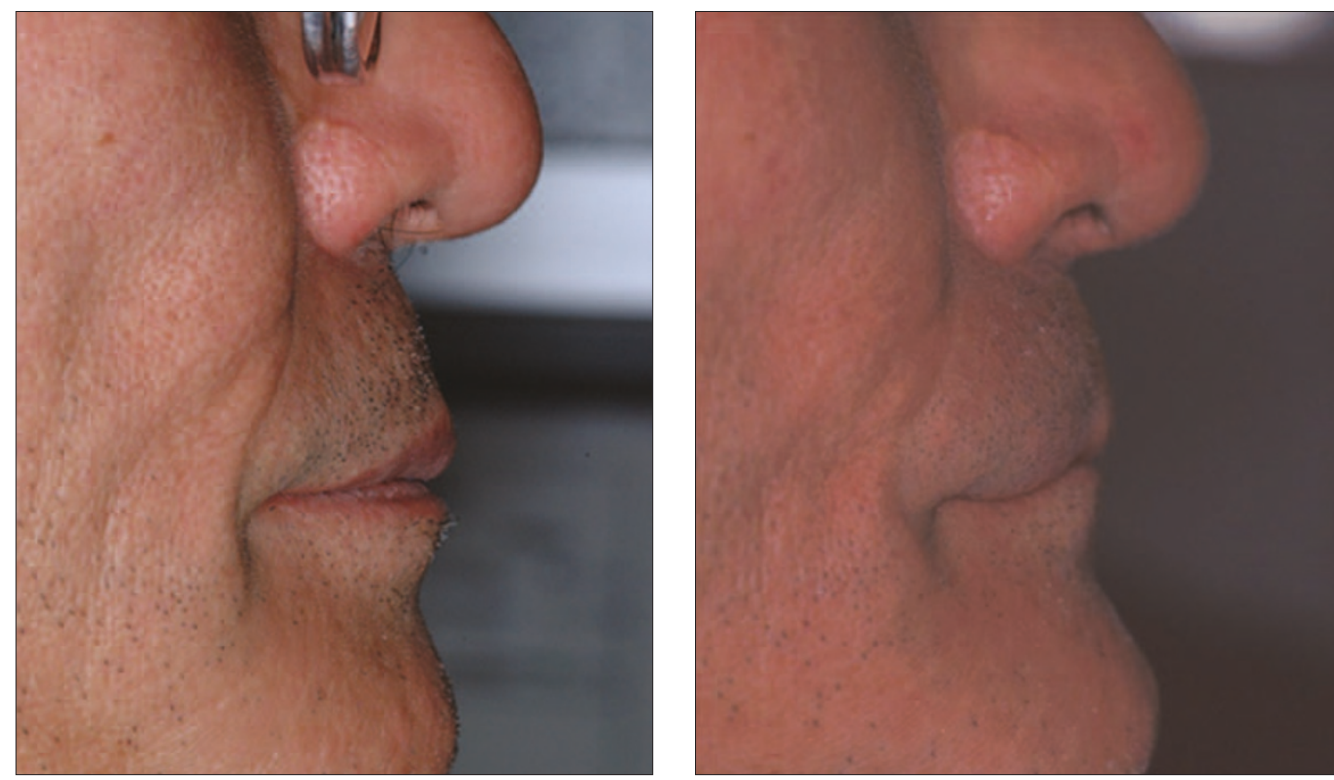

Fig. 5 (left) Lip support with denture lip looks well supported

Fig. 6 (right) Lip support without denture. This patient will require a flange to satisfy aesthetic parameters
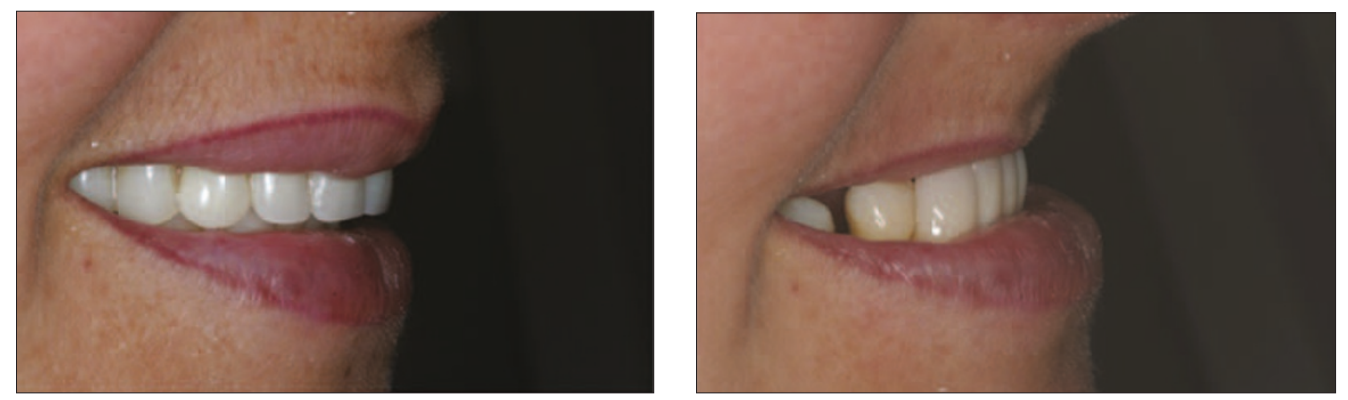

Fig. 7 (left) Cross section of tooth indictaing bone levels

Fig. 8 (right) With minimal resorption conventional crown and bridgework can be completed on the implants
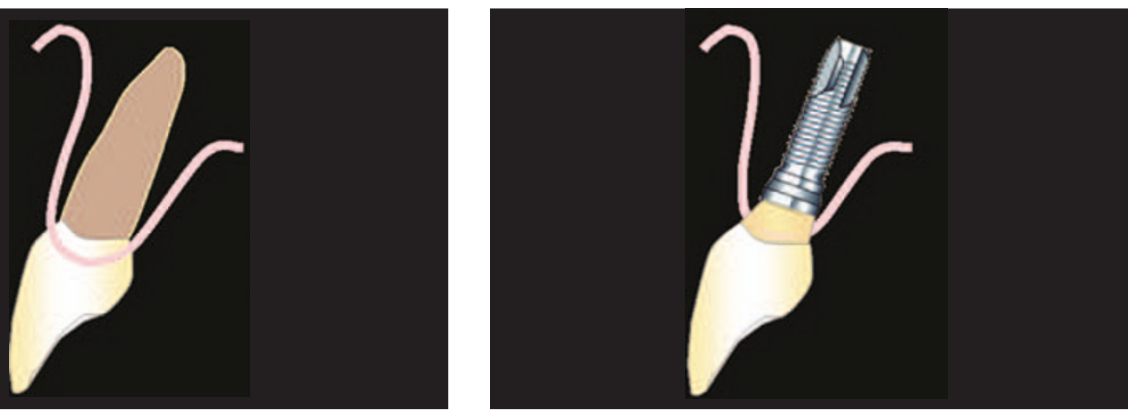

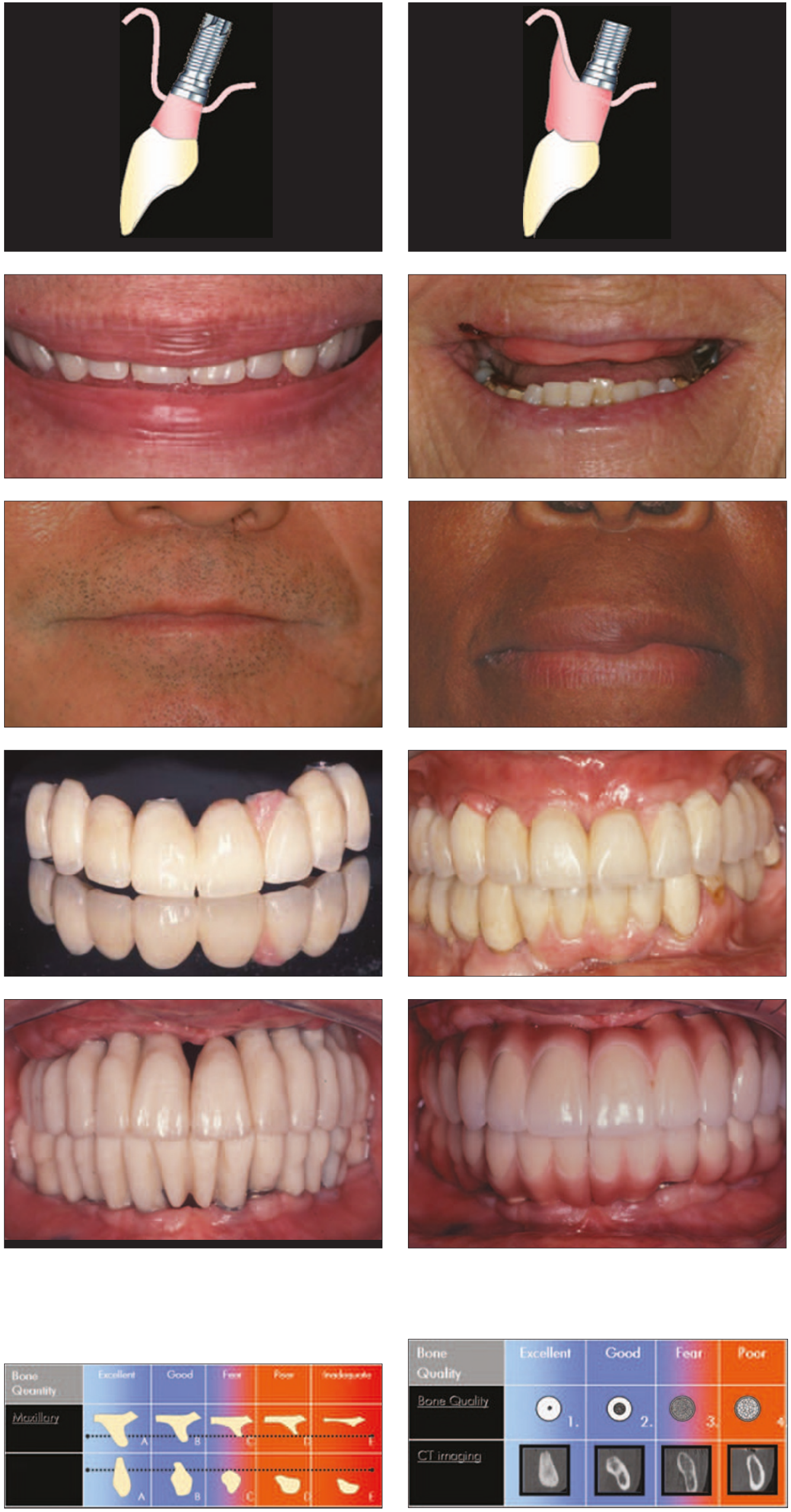
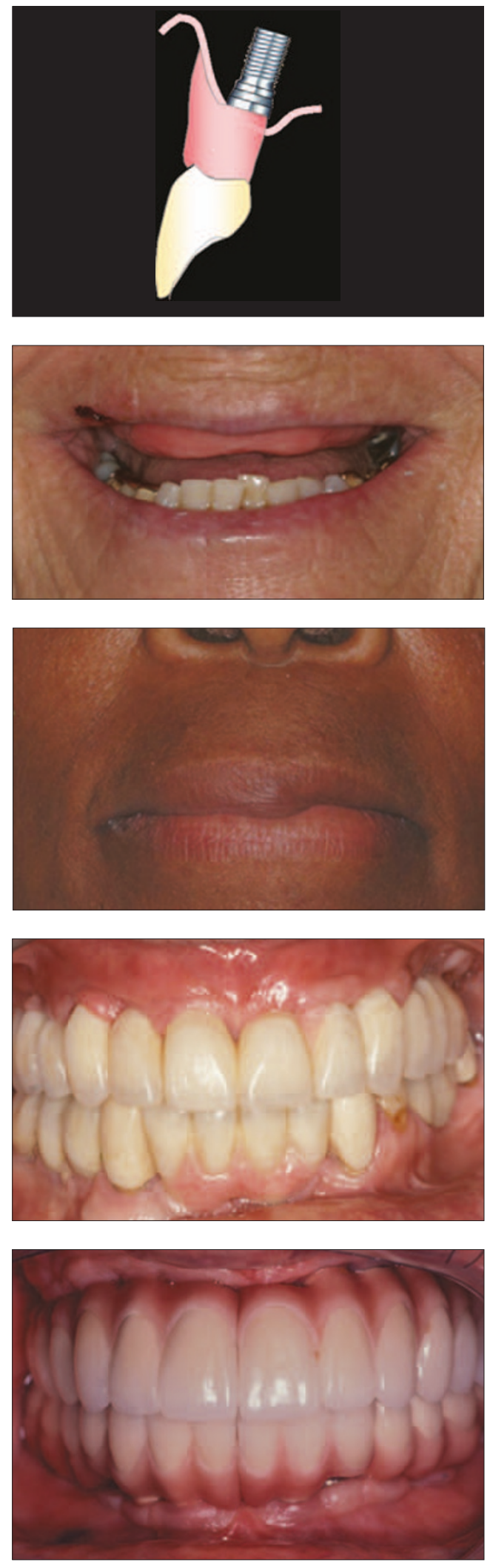

Fig. 9 (left) With moderate resorption pink porcelain may be required to disguise tooth length if the patient desires a fixed restoration

Fig. 10 (right) With excessive resorption a flange of a remova restoration is required to satisfy parameters of lip and facial support

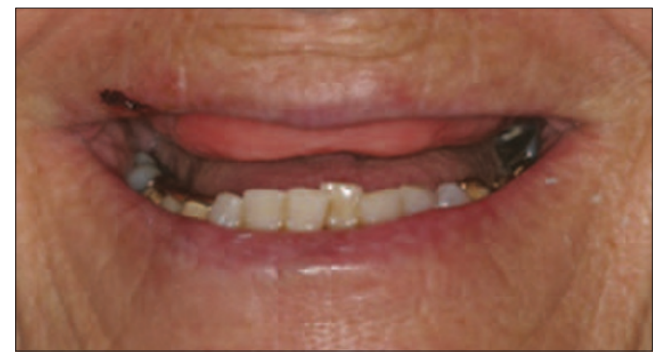

Fig. 11 (left) Low smile line

Fig. 12 (right) Ridge displayed when patient is smiling. This situation is aesthetically challenging since the interface between the gingival and restoration is visible

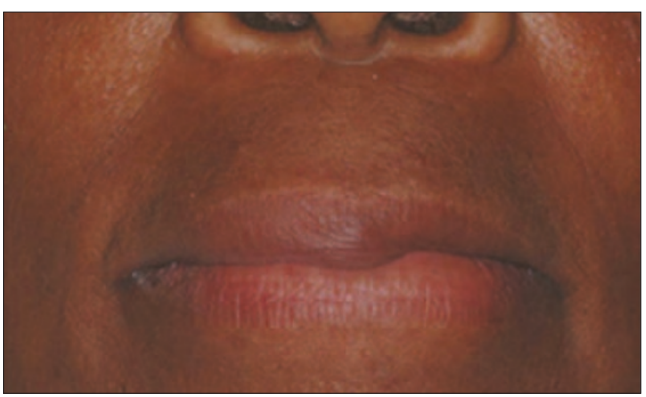

Fig. 13 (left) Patient displaying a short upper lip

Fig. 14 (right) Patient displaying a long upper lip

Fig. 15 (left) Implant placed in interproximal area, between left central and lateral incisors. Pink acrylic resin has been used to disguise the discrepancy

Fig. 16 (right) Provisional restoration in the mouth to determine if patient is accepting of pink acrylic resin

Fig. 17 (left) Provisional restorations in the mouth. Interdental papillae are very difficult to generate in full arch implant rehabilitations. The aesthetics must be visualised in provisional restorations. In this particular case the patient did not show the cervical portion due to a low smile line, however he continued to have problems with speech and food entrapment

Fig. 18 (right) Final restoration for patient in Fig. 17. Pink porcelain was used to close interdental spaces and provide improved aesthetics and speech

Fig. 19 (left) Cross section of bone resorption pattern according to $U$, Lekholm and GA, Zarb. ${ }^{12}$

Fig. 20 (right) Diagram indicating quality of bone according to $U$,

Lekholm and GA, Zarb. ${ }^{12}$ 


\section{PRACTICE}

Fig. 21 (left) Restrictive surgical guide with titanium pins

Fig. 22 (right) Radiographic guide tuberosity area. This patient

wanted to avoid a sinus lift and augmentation procedures

Fig. 24 (right) Lateral view to illustrate support from tuberosity implant

Fig. 25 (left) Occlusal view of splinted restoration

Fig. 26 (right) Clinical view of restoration in the mouth

Fig. 27 (left) Intra-oral view of restorative space between maxillary ridge and opposing dentition

Fig. 28 (right) Putty casts can be used to determine available space for restoration

Fig. 29 (left) For a completely edentulous patient, putty casts can be made of the intaglio of the denture and mounted

Fig. 30 (right) The putty casts give us an indication of space available prior to embarking upon restoration design

Fig. 31 (left) A conventional screw retained restoration requires $10-12$ implant and the opposing occlusion

Fig. 32 (right) A removable restoration on implants requires 14$16 \mathrm{~mm}$ of space between the head of the implant and the opposing occlusion with gutta percha markers an implant placed in the maxillary $\mathrm{mm}$ of space between the head of the
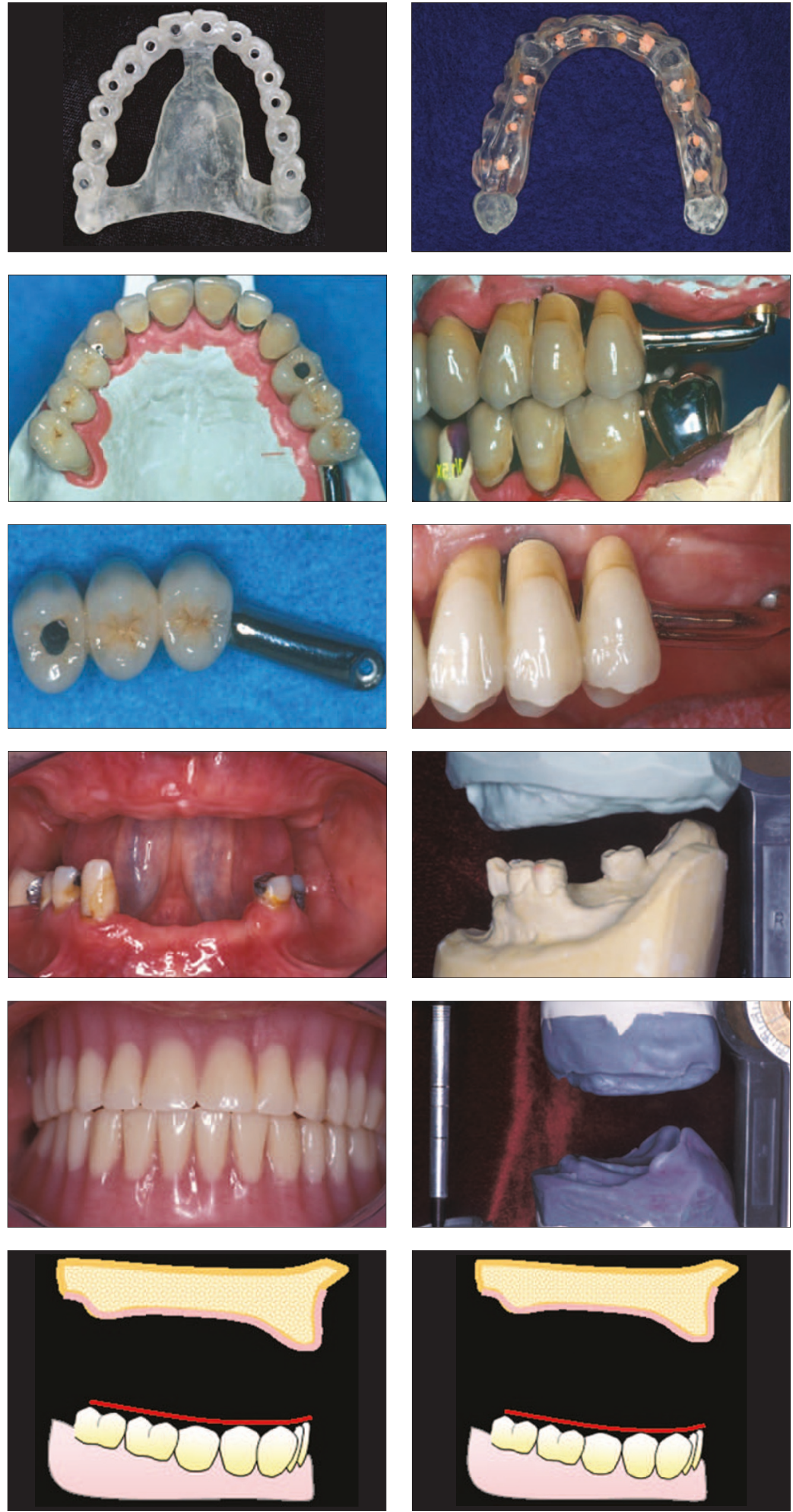

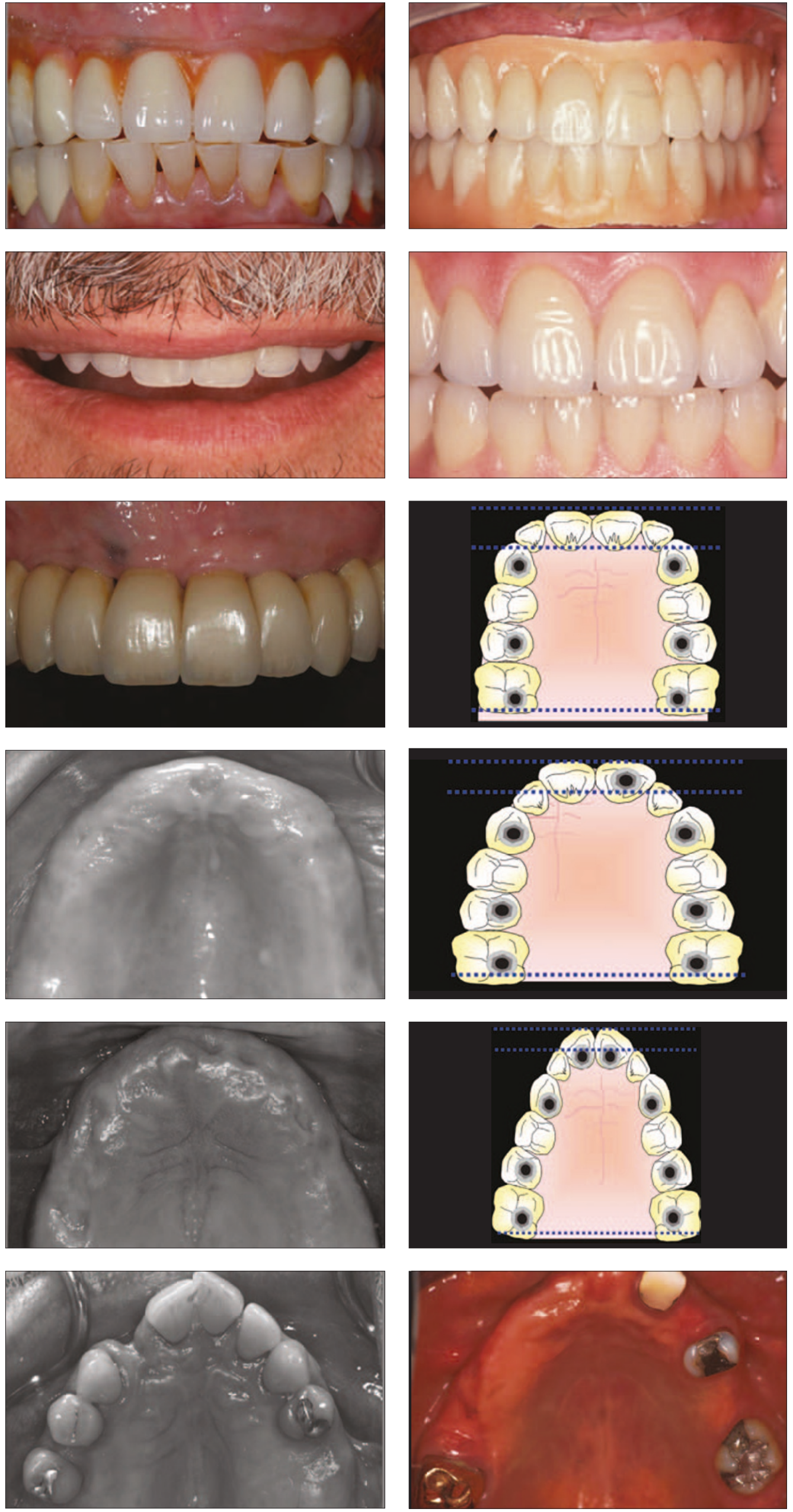

Fig. 33 (left) A diagnostic set up. The teeth have been set directly against the ridge, if this satisfies parameters of aesthetics this patient will be a candidate for a fixed restoration

Fig. 34 (right) Wax try in indicating space between the cervical portion of the tooth and the ridge. This area has been filled in with wax. If this satisfies parameters of aesthetics the patient will be a candidate for a fixed restoration. The patient must be told that pink porcelain will be required to disguise tooth length

Fig. 35 (left) Smile line of patient in Figure 34

Fig. 36 (right) Aesthetics of complete dentures can be very pleasing, patients transitioning from complete dentures to an implant supported restoration must be informed that the interdental spaces resembling papilla will not be reproduced in a full arch restoration

Fig. 37 (left) Full arch restorations on implants. Note papillae are absent; this has been disguised by varying the level of the interproximal contact

Fig. 38 (right) Square arch form, a minimum of six implants are required

Fig. 39 (left) Clinical square arch form

Fig. 40 (right) Ovoid arch form, an additional implant is required in the premaxilla to biomechanically stabilise the prosthesis

Fig. 41 (left) Clinical ovoid arch form

Fig. 42 (right) Tapering arch form, an additional two implants are required in the premaxilla to biomechanically stabilise the prosthesis

Fig. 43 (left) Clinical tapered arch form

Fig. 44 (right) Maxillary occlusal view 
opposing denture and subsequently the mandibular cast is mounted. This technique can be used for fully edentulous patients too (Fig. 27-30). The mounted casts can now be used to evaluate the available interarch space and decisions can be made with regards to the anticipated prosthesis design.

Conventional screw retained implant prostheses have been constructed with 10-12 mm between the edentulous ridges and the opposing occlusal plane. It provides sufficient space for bulk of restorative material and also permits a prosthesis design to establish aesthetics and hygiene. If space is limited, re-establishing a patient's vertical dimension or altering the opposing occlusion should be considered. ${ }^{13}$

A conventional overdenture requires additional space. Guidelines for space requirements are between 12-16 mm. Heat processed resin requires 2-3 $\mathrm{mm}$ to provide adequate strength as a denture base material. ${ }^{14}$ Space is also required for the prosthetic tooth. In the maxilla it is advisable to splint implants when used for overdenture prostheses and as a result 2-3 $\mathrm{mm}$ of space may be required to accommodate the necessary bulk for the tissue bar and any retaining clips (Figs 31-32).

\section{Incisal edge position}

The incisal edge position is determined using the principles taught in complete denture fabrication. Traditional guidelines tell us that when the patient makes the F sound the incisal edge should touch the vermillion border of the lower lip. Once the incisal edge position has been established the length for the central incisors is determined. On average the length of the central incisors is $10.5 \mathrm{~mm},{ }^{15}$ this can be more in elderly patients who exhibit gingival recession.

The axial inclination of the central incisor should be placed so as to provide adequate support for the upper lip. Once the crown length, angulation and coronal form have been determined the distance between the cervical crown margin and residual bone crest can be assessed. ${ }^{4}$ To determine if a fixed or removable restoration would be appropriate a wax try in is done without a flange. For a fixed restoration the clinical crown should ideally end up at the soft tissue level of the alveolar ridge. In this situation minimal resorption would have occurred, interarch space will be favourable and an optimal toothlip relationship is present (Figs 8,33 ). When a large vertical distance exists between the cervical aspect of the tooth and the alveolar ridge but the tooth-lip relationship is favourable pink ceramic may be used to disguise the tooth length and a fixed restoration is still possible (Figs 9, $34,35)$. When there is both a vertical and horizontal discrepancy between the ideal position of the tooth and the alveolar ridge, and the tooth lip relationship is not optimal this may be an indication for use of a removable prosthesis. The flange will provide adequate lip support and the teeth can be positioned appropriately to satisfy the parameters of aesthetics (Figs 5, 6, 10).

\section{Treatment planning}

The long term success of implant rehabilitation of the edentulous maxilla is dependent on consideration of all the factors previously discussed. Treatment planning must address these diagnostic findings. Treatment planning must also address the patient's original complaints and meet the patient's expectations. The patient needs to have a relatively good idea of what the final outcome is likely to be. Aesthetics is a major cause of failure, going through a lengthy expensive treatment only to achieve a result which is aesthetically inferior to a complete denture can be hugely disappointing.

Patient communication at the outset is of utmost importance. To avoid any unexpected surprises a great amount of time must be devoted to educating the patient into the relative advantages and disadvantages of proposed treatment.

Informed consent becomes important. The patient must fully understand and acknowledge the limitations of the proposed treatment, including possibility of implant failure. The patient must understand that treatment plan modifications may be required and the fact that placement of additional implants may be necessary. Informed consent must constitute the surgical risks of treatment and also the shortcomings of treatment to address adequately the patient's chief complaint and expectations.

In treatment planning the following factors must be considered:

1. Aesthetics and patient desires

2. Type of support

3. Amount of resorption and interarch space.

4. Number of implants

5. Implant distribution

6. Economics.

\section{Aesthetics and patient desires}

Meeting patient expectations are paramount when treatment planning. As discussed earlier, patients prefer to discard their removable appliance in favour of a fixed alternative. The clinician must know early in treatment if this is possible. Promising a patient a fixed reconstruction when diagnostic considerations present otherwise may result in a disappointed patient. Patients are also satisfied with the aesthetic appearance of a complete denture. In particular the appearance of the soft tissues is uniform and interdental papillae between denture teeth are reproduced well with pink acrylic resin (Fig. 36). When a patient then transitions to a fixed reconstruction, interdental papilla between implants is often absent. An illusion of interdental papilla can be created by altering the position of the contact point between adjacent teeth and using interproximal stain (Fig. 37).

\section{Type of support}

Essentially with the edentulous maxilla there are two categories of prosthesis, fixed and removable. Fixed prostheses included metal ceramic restorations supported by implants and, depending on the severity of the bone resorption some pink 
porcelain may be required to simulate gingival contours. In the removable category we have implant supported overdentures and implant retained and tissue supported overdentures. A removable prosthesis can be secured by different methods including, bar and clip, magnet, ball attachments or the use of a precision milled or spark eroded components.

The diagnostic factors previously discussed will allow the clinician to decide which type of prostheses will be more suitable.

\section{Amount of resorption and interarch space}

This parameter dictates the type of prosthesis to be fabricated. The clinician needs to evaluate if the patient exhibits, minimal, moderate or advanced resorption. Each type of prosthesis has a unique dimensional tolerance as previously discussed. Patients who exhibit minimal or moderate resorption are candidates for a fixed restoration providing parameters of facial and lip support are satisfied. Patients with advanced resorption can be satisfied aesthetically by fabrication of a removable prosthesis with a flange; this replaces necessary support that has been lost as a result of resorption. If patients in this category request a fixed restoration they will need to understand that extensive grafting procedures will be required and even after that the aesthetic outcomes may not meet their expectations.

\section{Number of implants}

There are many authors who have discussed treatment concepts for restoration of the edentulous maxilla with a fixed prosthesis. Recommendations have been made with respect to anticipated prosthesis designs and implants. Placement of six to eight implants (10-15 mm in length) is recommended for a fixed implant prosthesis with cantilever pontics. ${ }^{16,17}$ Recommendations have also been made with regard to removable restorations on implants - four to six implants have been recommended for both an implant and an implant and tissue supported restoration. ${ }^{17,18}$

Deciding on the number of implants to place is not governed by a formula and is dependent on multiple factors. The number of implants to place in each patient is determined by:

a. Quality of bone

b. Anticipated force to be placed on the restoration

c. Relationship between the shape of the residual ridge and the dental arch form.

\section{a. Quality of bone}

Frequently type 3 and 4 bone is encountered in the maxilla. On occasion the quality of the bone is such that conventional drills cannot be used to place the implant and osteotomes are required to develop the site to receive the implant. The success of implants in the maxilla is less certain than in the edentulous mandible. When the quality of bone is not optimal often the surgeon and restorative dentist consider placing additional implants. These implants are placed to allow the restorative dentist to continue with the anticipated prosthesis should one or two implants fail. Over-engineering in the maxilla can be advantageous but consideration should also be given to the costs that may be encountered should all the implants integrate. Often the restorative dentist will have to purchase additional abutments and the costs of these will need to be passed onto the patient.

When the patient has had posterior teeth missing for a considerable length of time the maxillary sinuses pneumatise and often there is insufficient bone for implant placement in these areas. If the patient refuses to undergo additional augmentation procedures, the concept of the shortened dental arch can be used and fewer implants placed.

\section{b. Anticipated force to be placed on the restoration.}

Part of the extra-oral examination should also involve analysis of the patients build and facial musculature. The masseter muscles should be observed for any hypertrophy that may be present. Bruxers often present with a pronounced antegonial notch and this can be indicative of the likely force to be placed on the restorations. In these types of patients it is wise to 'over engineer' and place additional implants for added support and distribution of force.

The opposing occlusion also has to be evaluated. Patients are likely to exert less force if the implant restorations are opposed by a complete denture as compared to the force that can be exerted when the patient has a natural dentition. The more the anticipated force on the implant restorations the more implants should be allowed for.

\section{c. Relationship between shape of residual ridge and the dental arch form}

Three typical arch forms are prevalent, square, ovoid and tapering. The edentulous maxillary residual ridge may also have three arch forms. Aesthetic requirements may require a dental arch form different from the residual ridge form. The dental arch form is determined by the final teeth position in the premaxilla and not from the residual ridge form. The final tooth position may need to be cantilevered to the facial in the final prostheses.

In a dental square arch lateral and central incisors are not cantilevered facially, compared with the canine position. Mandibular excursions and occlusal forces may be reduced on the canine implants. As a result implants in the canine position may suffice especially if they are splinted to posterior implants. The four pontics between the canines create reduced forces because forces are lowest in the incisor region and the square arch form has less cantilevered occlusal forces to the incisors (Figs 38-39). ${ }^{19}$

In a dental ovoid arch there should be three implants in the premaxilla, not two as in the square arch form (Figs 40-41). Sometimes this may require bone augmentation. For an ovoid 


\section{PRACTICE}

Fig. 45 (left) Mandibular occlusal view

Fig. 46 (right) Full mouth periapical radiographs; note failing maxillary dentition

Fig. 47 (left) Pre-orthodontic casts

Fig. 48 (right) Orthodontic set up on casts illustrating lingual position of mandibular incisors

Fig. 49 (left) Mandibular surgical guide

Fig. 50 (right) Maxillary surgical guide

Fig. 51 (left) Mandibular implant placement

Fig. 52 (right) Maxillary implant placement

Fig. 53 (left) First set of provisional restorations

Fig. 54 (right) Occlusal view showing retraction of mandibular anterior teeth
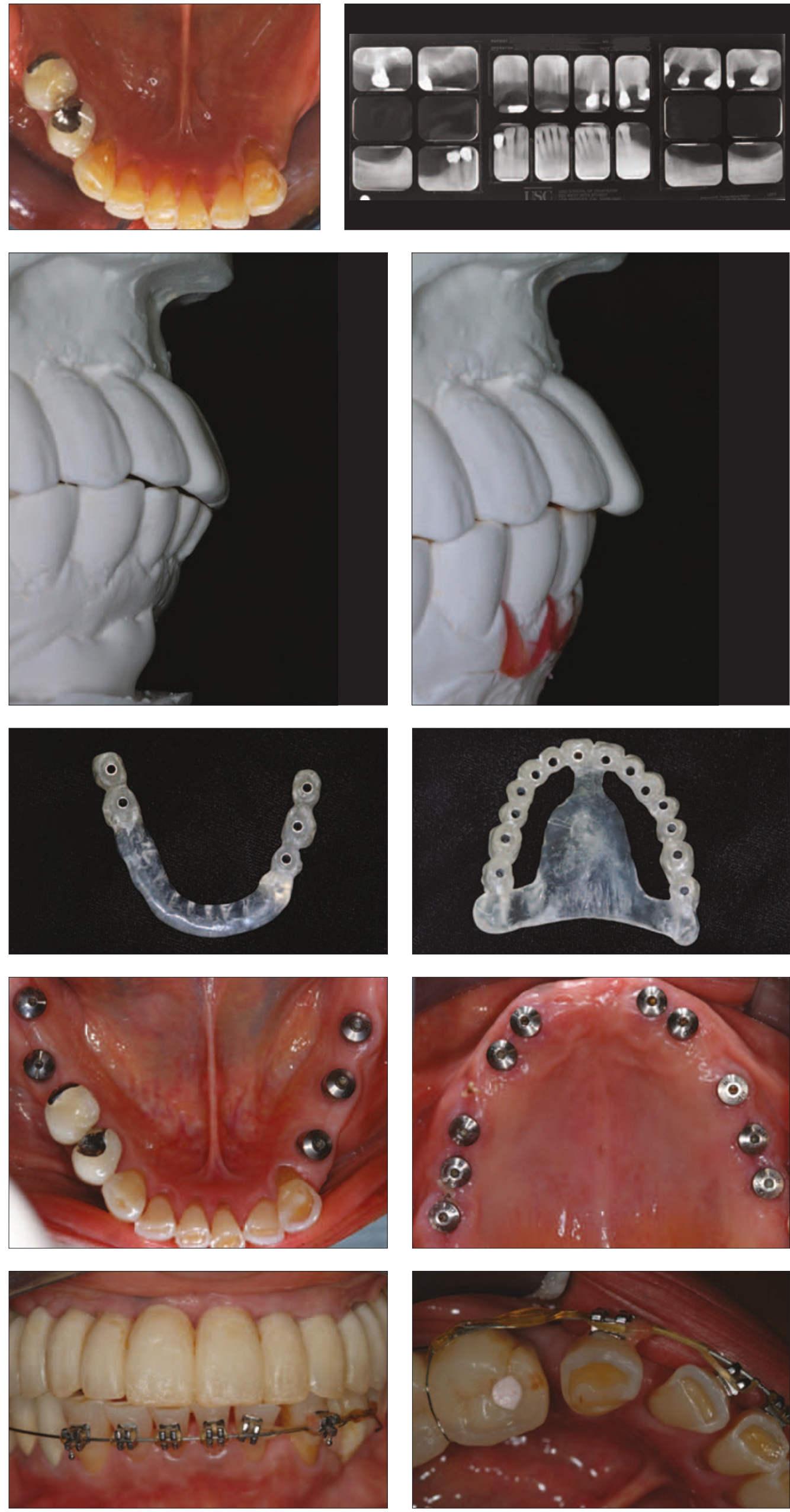

BRITISH DENTAL JOURNAL VOLUME 201 NO. 5 SEP 92006 

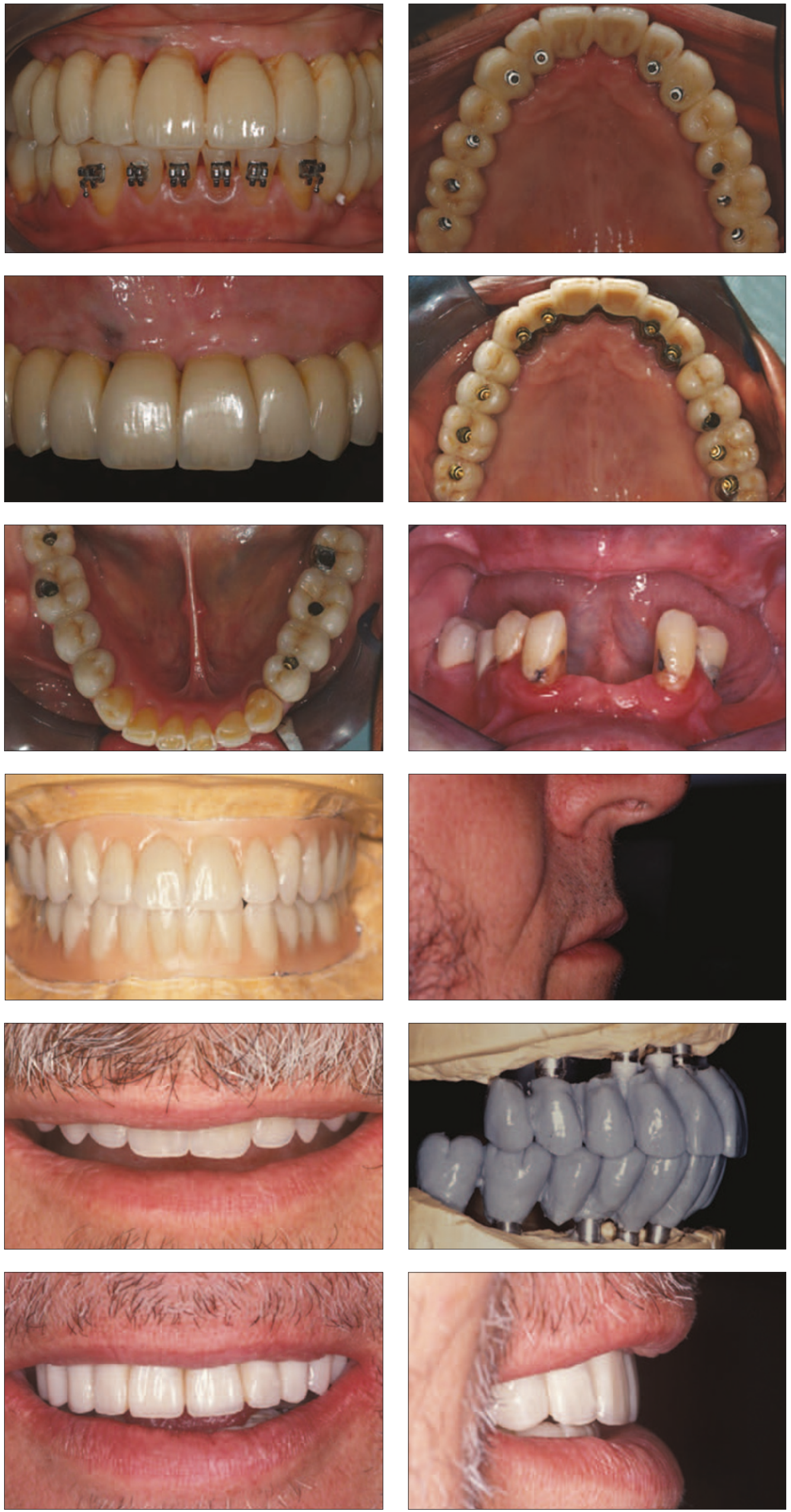
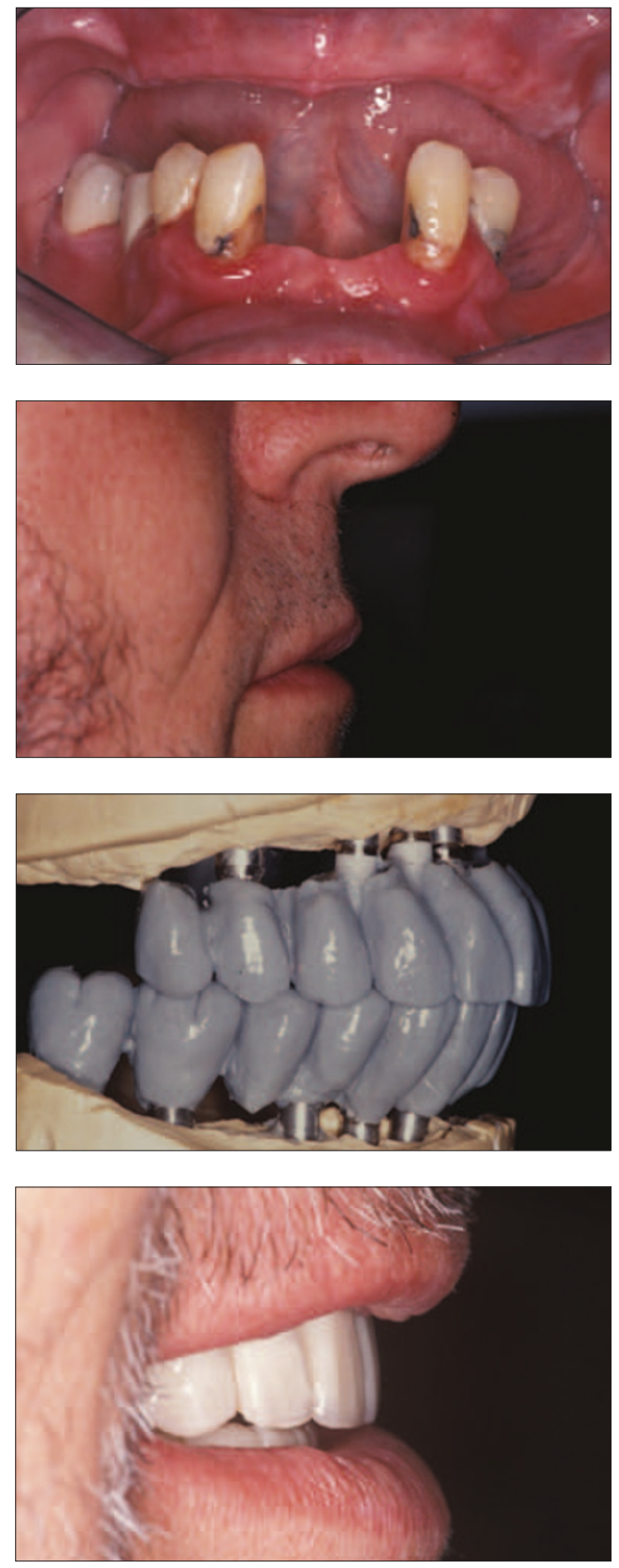

Fig. 55 (left) Second set of provisional restorations, patient complained of black triangle between maxillary central incisors, this was to be modified in the final prosthesis

Fig. 56 (right) Occlusal view of maxillary provisional restorations

Fig. 57 (left) Maxillary anterior view of completed restorations

Fig. 58 (right) Maxillary occlusal view of completed restorations

Fig. 59 (left) Mandibular occlusal view of completed restorations

Fig. 60 (right) Pre-operative situation of patient desiring implant supported restorations

Fig. 61 (left) Diagnostic set up on casts. Note amount of wax between cervical portion of teeth and ridge

Fig. 62 (right) Lip support with diagnostic appliance

Fig. 63 (left) Anterior view illustrating tooth display during smiling

Fig. 64 (right) Full contour wax up

Fig. 65 (left) Maxillary anterior view of provisional restorations, patient desired increased tooth display on smiling

Fig. 66 (right) Lateral view on smiling, illustrating lip support 
dental arch form planning for implants in the canine positions and at least one additional implant, preferably in the central incisor region, is important. The additional implant in the incisor region resists the additional forces created by this arch form and biomechanically the prostheses design will be more stable as there will be less stress on the abutment screws.

The restoration of a tapering arch form places the greatest stresses on the anterior implants especially when the pontics replace the incisors (Figs 42-43). The anterior teeth are cantilevered facially from the incisor position with increased forces in maximum intercuspation and in excursions. In this case four implants need to be placed in the premaxilla to replace the six anterior teeth. The worst case scenario is a patient with a tapered dental arch form to be restored on a square residual ridge form. Four implants are then required to compensate for the anterior tooth position. In this case bone grafting may be required. ${ }^{19}$

\section{Implant distribution}

Implant distribution and placement is critical in order to obtain optimum emergence profile for the definitive restorations as well as enabling the patient to maintain adequate hygiene. For a patient who presents with minimal resorption and is treatment planned for ceramo-metal restorations on implants, precise placement of implants is imperative and should be facilitated by the use of a surgical guide based on the diagnostic wax up. Implants placed in interproximal positions can cause problems from both an aesthetic and hygiene perspective.

For those patients who display moderate resorption but still qualify for a fixed restoration with the use of pink porcelain, implant placement is not critical but implant distribution is. Implants placed in interproximal tooth positions will not impact the aesthetics as this will be disguised by the use of pink porcelain. Implant distribution is critical since implants will need to be placed so the load can be shared equitably. Splinting the implants is also advantageous as this improves the biomechanics of the prosthesis design.

In implant supported overdentures placement is not critical but distribution is. Implants need to be placed with a sufficient antero-posterior spread so that load can be distributed equitably and cantilever length minimised.

In implant and tissue supported overdentures both implant placement and distribution become critical. Implants need to be placed so that when a bar is constructed it has a straight line connection between the implants and does not impinge on the palatal denture bearing area. The distribution of implants should also be such so that adequate room is available for the clip. Biomechanically the AP spread should allow the load to be distributed over a wide area. ${ }^{20,21}$

\section{Cost}

Restoration of the edentulous maxilla is costly whichever method is used to restore the patient.
Fixed reconstructions require more laboratory assistance and implant parts and hence are a lot more expensive.

However cost needs to be considered not only during fabrication of the prosthesis but also during maintenance. Overdentures seem to have more post insertion maintenance than their fixed counterparts. ${ }^{22}$ If this is consistent, it could be questioned whether an economic indication for choosing an overdenture could be justified when there is sufficient bone to support implants for a fixed prosthesis. The patient must be made aware that maintenance costs for removable prostheses on implants will be higher than that of a fixed prosthesis.

The following 4 case presentations will serve to reinforce diagnosis and treatment planning. Technical details of prosthesis fabrication will also be addressed.

\section{CASE 1 - CERAMO-METAL RESTORATIONS ON IMPLANTS}

This 67-year-old female was seeking replacement of her current removable partial denture with fixed restorations. Her specific complaint was the instability of the denture as well as the class three tooth relationships of her mandibular anterior teeth (Figs 44-46).

On clinical and radiographic examination teeth a diagnosis of lack of posterior support was made. There was also insufficient bone in the posterior maxillary and mandibular areas for placement of implant supported restorations.

The objectives of treatment included providing the patient with implant supported restorations in both, maxilla and mandible as well as orthodontically retracting the mandibular anterior teeth to provide for a more class 1 horizontal and vertical tooth relationship.

When significant numbers of teeth are missing the orthodontist is at a disadvantage because of lack of anchorage to effect the desired tooth movement. The literature has shown that dental implants can be used as anchors for both orthodontic and orthopaedic movement. ${ }^{23-25}$ By using an interdisciplinary approach implants can be used to provide anchorage and then be restored as implant supported restorations.

Diagnostic evaluation included evaluation of all the factors that had previously been discussed. The treatment plan was to fabricate the patient a fixed ceramo-metal prosthesis supported by implants.

With these objectives in mind a treatment plan was formulated which required communication between the surgeon, orthodontist and prosthodontist.

The first stage was to complete a bilateral maxillary sinus lift with bone augmentation as well as onlay grafting of the mandibular posterior sextants.

Implants are usually placed prior to the start of orthodontic treatment which can be difficult as the post-orthodontic position of the teeth needs to be determined beforehand. An orthodontic set up was completed on the cast 
to determine the post-orthodontic position of the teeth (Figs 47-48). Using this set up a surgical template was fabricated to communicate the positioning of the implants to the surgeon (Figs 49-50). The maxillary and mandibular implants were placed (Figs 51-52). ${ }^{25}$ The implant in position of tooth 21 could not be ideally positioned due to the distal root inclination of tooth 22 .

Once osseointegration had been established, provisional restorations fabricated from Poly Methyl Methacrylate were placed on the implants (Fig. 53). These restorations simplified the attachment of the orthodontic appliance, restored occlusal function, improved aesthetics, provided posterior vertical support and served as blueprints for the definitive implant borne restorations. ${ }^{26}$

Orthodontic brackets were attached directly to the provisional restorations using Poly Methyl Methacrylate resin and orthodontic treatment was begun immediately. Using nickel titanium wires a sustained orthodontic load was applied to effect lingual movement of teeth 2226 (Fig. 54). On completion of orthodontic treatment a second set of provisional restorations were fabricated since the vertical and horizontal relationships of the anterior teeth were now a more class 1 relationship (Fig. 55). Placement of the definitive restorations was facilitated by the existing provisional restorations, these restorations were used to communicate aesthetic and functional information to both patient and laboratory technician for a predictable outcome (Figs 56-59).

A summary of treatment planning considerations is listed below.

$\begin{array}{ll}\begin{array}{l}\text { Fixed ceramo-metal } \\ \text { prosthesis }\end{array} & \text { Treatment planning } \\ \text { Aesthetics } & \begin{array}{l}\text { Patient has adequate } \\ \text { facial and lip support } \\ \text { Implant supported }\end{array} \\ \begin{array}{ll}\text { Type of support } & \text { Minimal resorption, } 10 \\ \text { Resorption and interarch } & \text { mm inter-arch space } \\ \text { space } & \text { Minimum six if bone } \\ \text { Number of implants } & \text { quality and arch form } \\ \text { adequate } & \text { Critical }\end{array} \\ \begin{array}{l}\text { Implant placement and } \\ \text { distribution }\end{array} & \text { Most expensive } \\ \text { Cost } & \end{array}$

\section{CASE 2 - CERAMO-METAL PROSTHESES WITH} PINK CERAMIC

A 64-year-old male presented requesting implant rehabilitation of his dentition. He had previously worn a maxillary complete denture but was unable to tolerate i t due to a severe gagging problem (Fig. 60). The mandibular teeth were deemed unrestorable due to extensive caries and were consequently extracted.

A diagnostic trial denture was fabricated and tried in to verify aesthetics and phonetics. It can be seen from the trial denture set up that a significant amount of wax was placed between the cervical portions of the teeth and the alveolar ridge (Fig. 61). Essentially this wax is indicative of the amount of osseous tissue missing and if the patient has inadequate lip support and requests a fixed restoration osseous grafting is often carried out. In this instance the diagnostic denture was tried in to evaluate facial and lip support (Fig. 62). The incisal edge position was also verified (Fig. 63). The patient was accepting of the support provided by the trial denture. A CT scan was taken to confirm adequacy of bone for placement of implants. It was communicated to the patient that a fixed prosthesis would be fabricated. The options for the prosthetic phase would be to use pink porcelain to disguise the length of the teeth. Following implant integration a diagnostic was up was completed and provisional restorations were fabricated to verify, aesthetics, phonetics and occlusion (Figs 64-66). Once the patient was satisfied with the provisional restorations, definitive restorations were made. The gingival surfaces of the restorations were contoured so as to allow the patient to clean the prosthesis adequately (Figs 67-69).

$\begin{array}{ll}\begin{array}{l}\text { Fixed ceramo-metal } \\ \text { prosthesis with pink } \\ \text { Ceramic }\end{array} & \text { Treatment planning } \\ \text { Aesthetics } & \begin{array}{l}\text { Patient has adequate } \\ \text { facial and lip support }\end{array} \\ \text { Type of support } & \text { Implant supported } \\ \text { Resorption and interarch } & \text { Moderate resorption, >10 } \\ \text { space } & \text { mm inter-arch space } \\ \text { Number of implants } & \text { Minimum six if bone } \\ & \begin{array}{l}\text { quality and arch form } \\ \text { adequate. }\end{array} \\ \text { Implant placement and } & \text { Placement not critical, } \\ \text { distribution } & \text { distribution is } \\ \text { Cost } & \text { Most expensive }\end{array}$

CASE 3 - IMPLANT SUPPORTED OVERDENTURE Implant supported overdentures are fabricated when excessive tissue defects prevent the use of a fixed prosthesis, or when the quality and/or the amount of bone will not permit the ideal placement of the implants to provide adequate support for a fixed restoration.

Overdentures may be implant supported or implant and tissue supported. Space requirements for implant supported overdentures are greater than that of fixed restorations on implants. A minimum of $13 \mathrm{~mm}$ of space from the opposing dentition is needed. This space is required for the metal framework, heat processed acrylic resin and the prosthetic tooth.

As far as implant number and position is concerned, a minimum of six implants well distributed around the arch is recommended. Other factors influencing the number of implants used will include bone quality and dental arch form. An advantage of ovedentures is that facial support can be provided with the flange and implant placement is not so critical. One disadvantage with implant supported overdentures is the maintenance required. Often patients can exert far great forces with an implant supported 


\section{PRACTICE}

Fig. 67 (left) Final restoration, not convex contours of gingival areas so that patient maintain hygiene

Fig. 68 (right) Final restorations clinically

Fig. 69 (left) Final restorations illustrating tooth display on smiling

Fig. 70 (right) Acrylic resin fracturing off of framework. This is quite common in implant supported overdentures

Fig. 71 (left) Pre-operative situation in patient desiring implant supported restorations; note failing dentition

Fig. 72 (right) Lip support with diagnostic set up

Fig. 73 (left) Diagnostic set up without flange, this patient desired a fixed prosthesis

Fig. 74 (right) CT scan of patient in Fig. 73; note absence of bone in posterior maxilla

Fig. 75 (left) Receptacle for swivel latch milled into implant bar. Note two receptacles, patients are often provided two maxillary prostheses. A complication of this type of prosthesis is acrylic resin fracturing off

Fig. 76 (right) Two types of retention mechanism are incorporated into implant supported bars. There are receptacles for the swivel latches and cylindrical slots

Fig. 77 (left) Auxiliary retention mechanisms

Fig. 78 (right) Swivel latch open
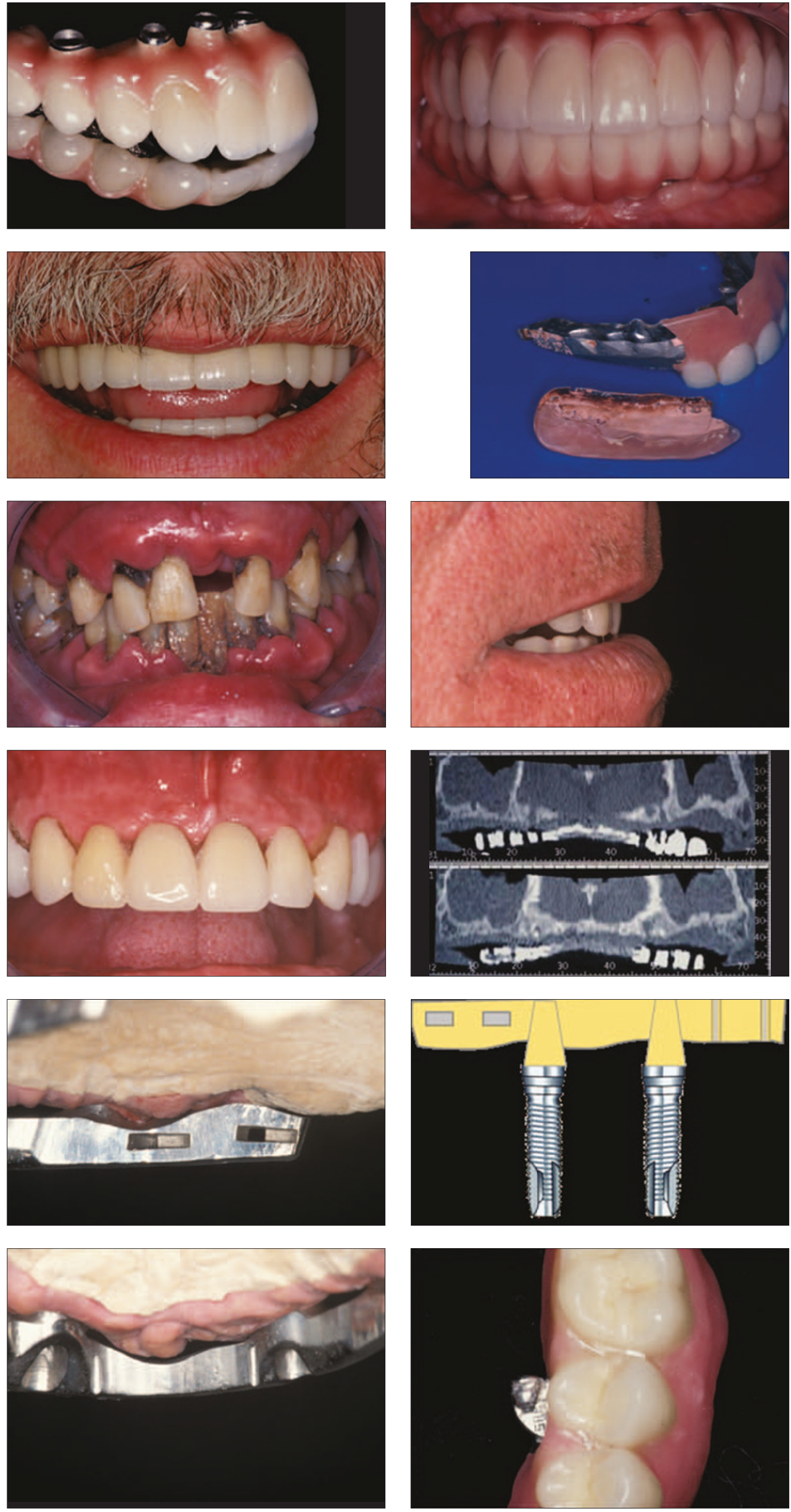

BRITISH DENTAL JOURNAL VOLUME 201 NO. 5 SEP 92006 

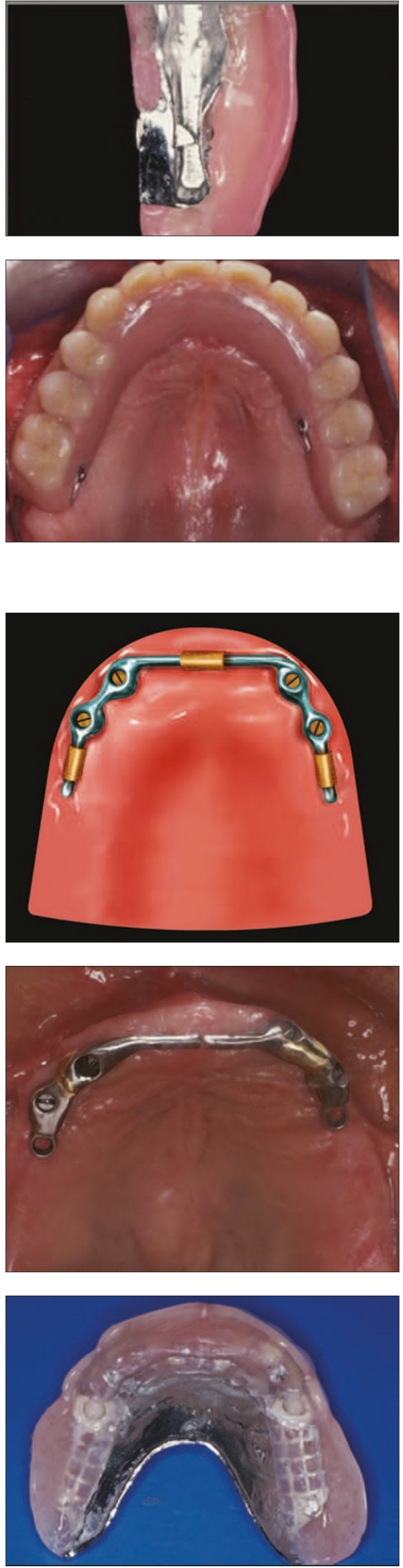
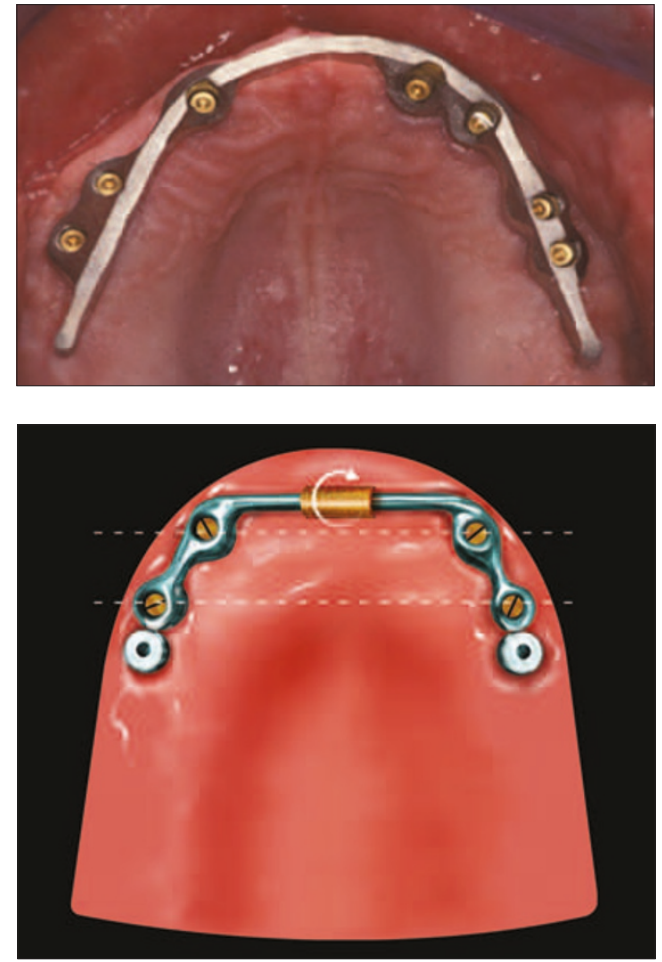

Fig. 81 (left) Implant supported overdenture. With a sufficient

number of implants the palate can be eliminated

Fig. 82 (right) Ideal design of implant and tissue supported overdentures; this design allows free rotation of the overdenture

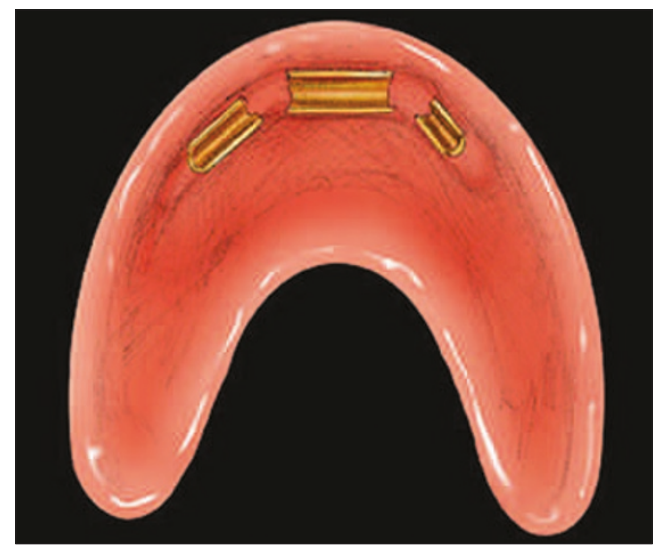

Fig. 83 (left) This design will not allow free rotation of the overdenture. The clips will require regular maintenance

\section{Fig. 84 (right) Internal of} overdenture for Figure 83; this distribution of clips will not allow rotation of the overdenture and will not allow equitable distribution of support between the implants and the mucosa

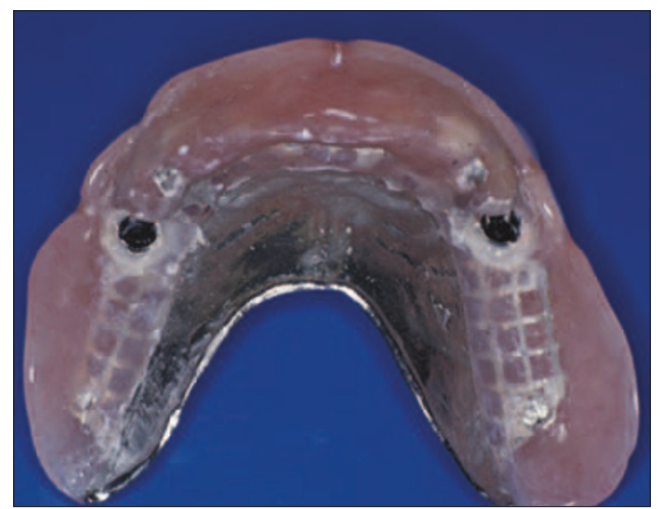

Fig. 85 (left) Occlusal view showing implant bar, often this bar is made in two sections, joined intraorally and soldered. Note the distal ERA attachments

Fig. 86 (right) The maxillary denture is fabricated with spacers for the ERA attachments. Note support is also required from the palate

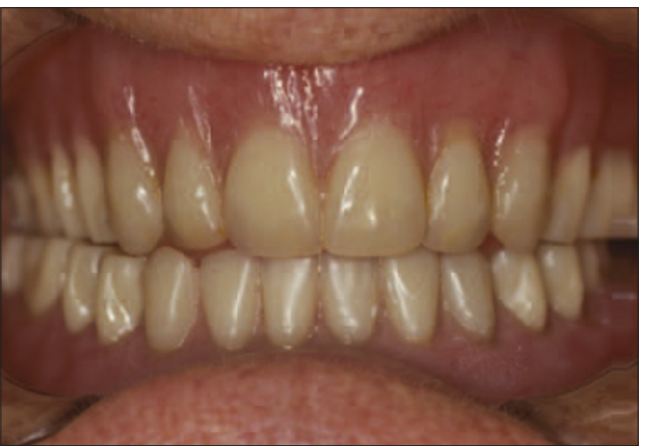

Fig. 87 (left) The spacers are removed and the attachments are picked up in the mouth; space is also created to allow free rotation of the denture around the anterior clip

Fig. 88 Final maxillary denture intraorally, this denture is implant and mucosa supported 
denture and this can result in the acrylic resin fracturing off the framework (Fig. 70).

A 45-year-old male presented with a failing dentition and was seeking implant rehabilitation. The patient was edentulated and immediate dentures were fabricated. The immediate dentures allowed assessment of lip and facial support and evaluation of incisal edge position (Fig. 71). Following a period of healing a diagnostic denture was fabricated. This denture provided adequate lip support (Figs 72-73) and a fixed restoration was anticipated. Following a CT scan it was revealed that inadequate bone existed for fabrication of a fixed prosthesis (Fig. 74). There was insufficient bone in both the anterior and posterior maxillary area and the patient refused surgery to augment this. The patient presented with extremely thick soft tissue. At the time of implant placement the soft tissue was thinned and seven implants were placed. A bar was fabricated to splint the implants together. This bar incorporated receptacles for a swivel latch attachment and addition auxiliary retention was also included (Figs 75-79) A superstructure was spark eroded to fit on top of the framework and allow precision locking of the swivel lock into the receptacle incorporated in the bar. Following silicoating, a denture wax up was processed onto the bar using heat processed acrylic resin (Figs 80-81). With a sufficient number of implants support does not have to be gained from the palate and the patient can benefit from greater perception of taste and temperature change.

\begin{tabular}{|c|c|}
\hline $\begin{array}{l}\text { Implant supported } \\
\text { overdenture }\end{array}$ & Treatment planning \\
\hline Aesthetics & $\begin{array}{l}\text { Flange required for } \\
\text { adequate lip and facial } \\
\text { support }\end{array}$ \\
\hline Type of support & Implant supported \\
\hline $\begin{array}{l}\text { Resorption and interarch } \\
\text { space }\end{array}$ & $\begin{array}{l}\text { Severe resorption 13-15 } \\
\mathrm{mm} \text { inter-arch space }\end{array}$ \\
\hline Number of implants & $\begin{array}{l}\text { Minimum six if bone } \\
\text { quality and arch form } \\
\text { adequate }\end{array}$ \\
\hline $\begin{array}{l}\text { Implant placement and } \\
\text { distribution }\end{array}$ & $\begin{array}{l}\text { Implants should be well } \\
\text { distributed }\end{array}$ \\
\hline Cost & $\begin{array}{l}\text { Less expensive than } \\
\text { ceramo-metal prostheses. } \\
\text { More maintenance costs }\end{array}$ \\
\hline
\end{tabular}

\section{CASE 4 - IMPLANT AND TISSUE SUPPORTED OVERDENTURE}

When designing implant overdentures for the maxilla a configuration of implant place ment/ bar design is required which will require free rotation of the prostheses.

In the maxilla a minimum of four implants is required. Even with the use of four implants it is advised to gain support from the palate. Space requirements are similar to implant supported overdentures with 13-15 mm being required. Implant placement requires a straight line connection between the anterior two implants so that a bar can be fabricated. This bar should not encroach on the palate as this may result in increased bulk of the denture in this area, subsequently affecting speech. Patients accepting this type of prosthesis should be warned ahead of time that there will be resiliency associated with the prosthesis on biting down. Patients going through extensive therapy often have unrealistic expectations and may be better off with additional implant placement and fabrication of a fully implant supported restoration.

Use of more than two implants complicates the design of the overdenture in that sometimes the bar configuration does not allow free rotation of the prostheses. ERA attachments are positioned adjacent to the distal implants. These attachments permit the overlying prosthesis to be compressed into the mucoperiosteum in the extension areas. As a result, the denture bearing tissues absorb the occlusal forces (Fig. 82). ${ }^{27}$ The clip needs to be oriented correctly in the anterior region so the denture is free to rotate, sometimes when this rotation is not allowed, damage to the clip results (Figs 83-84). ${ }^{28}$

A 52-year-old male presented requesting increased stability of his maxillary denture. All treatment options were offered to the patient. As a result of lack of facial support and limited finances, an implant and tissue supported overdenture was treatment planned.

Four implants were placed; these implants maximised the anteroposterior spread and allowed sufficient space between the anterior two implants for incorporation of a clip. A cast bar was fabricated and verified for passive fit on the implants. The configuration of the bar was such that it would allow free rotation of the overlying prosthesis. Once passive fit was confirmed a master cast was fabricated by picking up the bar in a border moulded impression. A cast framework was supported by the bar onto which heat cured acrylic resin was processed (Figs 85-88).

\begin{tabular}{|c|c|}
\hline $\begin{array}{l}\text { Implant supported } \\
\text { overdenture }\end{array}$ & Treatment planning \\
\hline Aesthetics & $\begin{array}{l}\text { Flange required for } \\
\text { adequate lip and facial } \\
\text { support }\end{array}$ \\
\hline Type of support & $\begin{array}{l}\text { Implant and tissue } \\
\text { supported }\end{array}$ \\
\hline $\begin{array}{l}\text { Resorption and interarch } \\
\text { space }\end{array}$ & $\begin{array}{l}\text { Severe resorption 13-15 } \\
\mathrm{mm} \text { interarch space }\end{array}$ \\
\hline Number of implants & Minimum four \\
\hline $\begin{array}{l}\text { Implant placement and } \\
\text { distribution }\end{array}$ & $\begin{array}{l}\text { Implants should be well } \\
\text { distributed }\end{array}$ \\
\hline Cost & $\begin{array}{l}\text { Less expensive than } \\
\text { ceramo-metal prostheses. } \\
\text { More maintenance costs }\end{array}$ \\
\hline
\end{tabular}

Implant rehabilitation of the edentulous maxilla is one of the most challenging endeavours facing the restorative dentist. Comprehensive evaluation and precise evaluation of the patients needs, followed by appropriate treatment 
planning provide the restorative dentist with the platform to satisfy patient expectations. ${ }^{2}$ Communication is required between restorative dentist and surgeon to ensure optimal placement of implants. Only with precision in implant placement can aesthetics in the final prosthesis be provided.

Patients transitioning from a complete denture to a fixed reconstruction will have high expectations and clear communication is critical at the outset so that realistic expectations are set and patients' objectives met. Nothing is more disappointing for both patient and clinician than going through a lengthy expensive treatment only to have a less than optimal outcome.

Whether planning for a fixed or removable prosthesis, attention to detail is required at every step. When all sequences of treatment are executed appropriately, implant rehabilitation of the edentulous maxilla is one of the most gratifying procedures for both the restorative dentist and the patient.

1. Branemark P I, Hansson B O, Adell R et al. Osseointegrated implants in the treatment of the edentulous jaw. Experience from a 10 year period. Scand J Plast Reconstr Surg Supple 1977: 16: 1-132.

2. Bosse L P, Taylor T D. Problems associated with implant rehabilitation of the edentulous maxilla. DCNA 1998; 42: 117-127.

3. Tallgren A. The reduction in face height of edentulous and partially edentulous subjects during long term denture wear: a longitudinal roentgenographic cephalometric study. Acta Odontol Scand 1966; 24: 195-239.

4. Zitzmann N U, Marinello C P. Treatment plan for restoring the edentulous maxilla with implant supported restorations: Removable overdenture versus fixed partial denture design. J Prosthet Dent 82: 188-196.

5. Tjan A H, Miller G D, The J G. Some aesthetic factors in a smile. J Prosthet Dent 1984; 51:24-28.

6. Schwarz M S, Rothman S L, Rhodes M L, Chafetz N. Computed tomography: Part II. Pre-operative assessment of the maxilla for endosseous implant surgery. Int J Maxillofac Implants 1987: 2: 143-148.

7. Kent J N, Block M S. Simultaneous maxillary. Sinus floor bone grafting and placement of hydroxylapatite coated implants. J Oral Maxillofacial Surg 1989: 47: 238.

8. Wood R M, Moore D L. Grafting of the maxillary sinus with intra-orally harvested autogenous bone prior to implant placement. Int J Oral Maxillofac Implants 1988; 3: 209.

9. Krekmanov L, Kahn M, Rangert B et al. Tilting of posterior mandibular and maxillary implants for improved prosthesis support. Int J Oral Maxillofac Implants 2000; 15: 411.

10. Henry PJ. A review of guidelines for implant rehabilitation of the edentulous maxilla. J Prosthet Dent 2002: 87: 281-288.

11. Balshi T J, Wolfinger G J, Balshi S F 2nd. Analysis of 356 pterygomaxillary implants in edentulous arches for fixed prosthesis anchorage. Int J Oral Maxillofac Implants 1999; 14: 398-406.

12. Lekholm U, Zarb GA. Patient selection and preparation. In Branemark P-I, Zarb G A, Albrektsson T (Eds). Tissueintegrated prostheses: Osseointegration in clinical dentistry. pp 199-209. Chicago: Quintessesnce, 1985.

13. Wicks R A. A systematic approach to definitive planning for osseointegrated implant prostheses. J Prosthodont 1994: 3: $237-242$.

14. Naert I, DeClercq M, Theuniers $G$ et al. Overdentures supported by osseointegrated fixtures for the edentulous mandible. A 2.5 year report. Int J Oral Maxillofac /mp/ 1988. 3: 191-196.

15. Ash M M. Wheelers dental anatomy, physiology and occlusion. $7^{\text {th }}$ ed. pp 128-273. Philadelphia: WB Saunders, 1993

16. Jemt T. Fixed implant-supported prostheses in the edentulous maxilla. A five-year follow-up report. Clin Oral Implants Res 1994: 5: 142-147.

17. Rangert $B$, Jemt $T$, Jorneus $L$. Forces and moments on Branemark implants. Int J Oral Maxillofac Implants 1989; 4: 241-247.

18. Hutton J E, Heath M R, Chai J Y et al. Factors related to success and failure rates at 3-year follow-up in a multicenter study of overdentures supported by Branemark implants. Int J Oral Maxillofac Implants 1995; 10: 33-42.

19. Misch C E. Dental implant prosthetics. pp 265-281. UK: Elsevier Mosby, 2005.

20. Palmqvist S, Sondell K, Swartz B. Implant-supported maxillary overdentures: outcome in planned and emergency cases. Int J Oral Maxillofac Implants 1994; 9: 184-190.

21. Adell $R$, Eriksson $B$, Lekholm U et al. A long term follow up study of osseointegrated implants in the treatment of totally edentulous jaws. Int J Oral Maxillofac Implants 1990; 5:347-359.

22. Jemt $T$, Book $K$, Linden $B$, Urde $G$. Failures and complications in 92 consecutively inserted overdentures supported by Branemark implants in severely resorbed edentulous maxillae: a study from prosthetic treatment to first annual check-up. Int J Oral Maxillofac Implants 1992; 7: 162-167.

23. Roblee R D. Interdisciplinary dentofacial therapy. A comprehensive approach to optimal patient care. pp 17-43. UK: Quintessence, 1994

24. Chiche FA, Leriche M A. Multidisciplinary implant dentistry for improved aesthetics and function. Pract Perio Aest Dent 1998; 10: 177-186.

25. Smalley W et al. Osseointegrated titanium implants for maxillofacial protraction in monkeys. Am J Orthod Dentofac Orthop 1988; 94: 285-295.

26. Douglas J, Killinay D. Dental implants used as orthodontic anchorage. J Oral Implantol 1988; 13: 28-38.

27. Chee W L. Considerations for implant overdentures. CDA 1992; 25-28.

28. Lewis S. Implant retained overdentures. Compend Contin Educ Dent XIV: 1270-1283. 